\title{
Payment of clinical research subjects
}

\author{
Christine Grady
}

\author{
Department of Clinical Bioethics, Clinical Center, NIH, Bethesda, Maryland, USA.
}

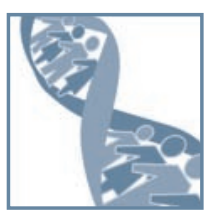

Offering payment to clinical research subjects, in an effort to enhance recruitment by providing an incentive to take part or enabling subjects to participate without financial sacrifice, is a common yet uneven and contentious practice in the US. Concern exists regarding the potential for payment to unduly influence participation and thus obscure risks, impair judgment, or encourage misrepresentation. Heightening these concerns is the participation not only of adults but also of children in pediatric research trials. Thorough assessment of risks, careful eligibility screening, and attention to a participant's freedom to refuse all serve to reduce the possibility of compensation adversely affecting the individual and/or the study. Institutional review boards currently evaluate payment proposals with minimal guidance from federal regulations. Here, reasons for providing payment, payment models, ethical concerns, and areas for further research are examined.

The payment of human subjects for their participation in scientific research in the US is a common and longstanding practice that has been documented for well over 100 years. As far back as the 1820 s, William Beaumont, whom many consider to be the father of gastric physiology, gave patient Alexis St. Martin - a French Canadian voyageur suffering from an incompletely healed gunshot wound to the stomach - food, lodging, clothing, and \$150 for the opportunity to study his stomach contents for 1 year (1). In 1900, renowned American military surgeon Walter Reed paid study participants $\$ 100$ in US gold to allow themselves to be bitten by infected mosquitoes in the famous yellow fever experiments and an additional \$100 if they consequently contracted the viral disease (1). According to Susan E. Lederer, author of Subjected to science: human experimentation in America before the Second World War (1), in the US, "paying human subjects for their participation in research ... became routine in the 1920s and 1930s." Other nonmonetary forms of compensation were also common, such as meals, transportation, and burial costs. From the early 1950s, when the world's largest clinical research complex, the NIH Clinical Center, opened, documents show that "normal" healthy volunteers were regularly paid for their participation in biomedical research or money was given to the church or group that organized and recruited these volunteers (2).

Today, newspaper advertisements describing studies that offer "free treatment" for depression or asthma, for example, often state "financial compensation provided." Websites list possible research trials for prospective subjects to review and commonly mention that compensation is provided, often naming a specific dollar amount (3). Although it is unclear exactly how common this practice is, data suggest that a sizable subset of research studies at most organizations or institutions that conduct clinical research pay subjects for participation (4). In addition, studies that offer payment to subjects cover a wide spectrum of types of research, from short-term physiological studies offering no benefit to subjects to longer, phase 3 clinical trials that may offer the prospect of direct therapeutic benefit to subjects (5). Interestingly, there appears to be some variation according to disease or medical subspecialty in the frequency with which payment is offered to research subjects. For

Nonstandard abbreviations used: IRB, institutional review board. Conflict of interest: The author has declared that no conflict of interest exists. Citation for this article: J. Clin. Invest. 115:1681-1687 (2005). doi:10.1172/JCI25694. example, it is more common in the US to offer payment in asthma, HIV, diabetes, or dermatological research trials than in oncology or cardiovascular trials (6). There are currently no data to explain why this variation exists. Although decisions about offering payment could be influenced by disease severity, sociodemographic characteristics, or the availability of treatment alternatives, some of the variation probably reflects the culture of the subspecialty.

Although the practice of paying subjects for research participation in the US is widespread, it remains a contentious issue (Figure 1). Some commentators believe that the act of paying research subjects is wrong (7), maybe even coercive, while others find it an acceptable and perhaps necessary part of recruitment for clinical investigation $(8,9)$; others see payment of at least healthy subjects as fair and appropriate $(10,11)$. In addition, only minimal guidance exists to help investigators determine whether or how much to pay participants in a particular study. The section of the US Code of Federal Regulations governing clinical research does not specifically address the issue of payment of research subjects (12). Institutional review boards (IRBs) - committees designated to review, approve the initiation of, and conduct periodic review of research involving human subjects - are responsible for ensuring that the amount and schedule of proposed payment is ethically acceptable; however, these bodies also operate with minimal and general guidance $(4,12,13)$. Consequently, payment practices vary widely in the US (5).

Reasons for offering payment to research subjects and common ethical concerns about offering payment are discussed herein. Models of payment, payment of healthy subjects versus patientsubjects, payment in pediatric research, and practical issues related to the payment of research subjects are also examined.

\section{Payment of research subjects: why or why not?}

Biomedical and behavioral research necessary to improve human health and medical care depends on the participation of human subjects. The usual justification offered for paying research subjects is that payment facilitates the timely recruitment of an adequate number and type of subject (9). Payment may be important to research to the extent that it encourages participation. Several studies have shown that response to written surveys is influenced by payment (14-19), as is willingness to participate in hypothetical studies $(20,21)$, but less is known about the real effect of payment on recruitment in clinical research. 


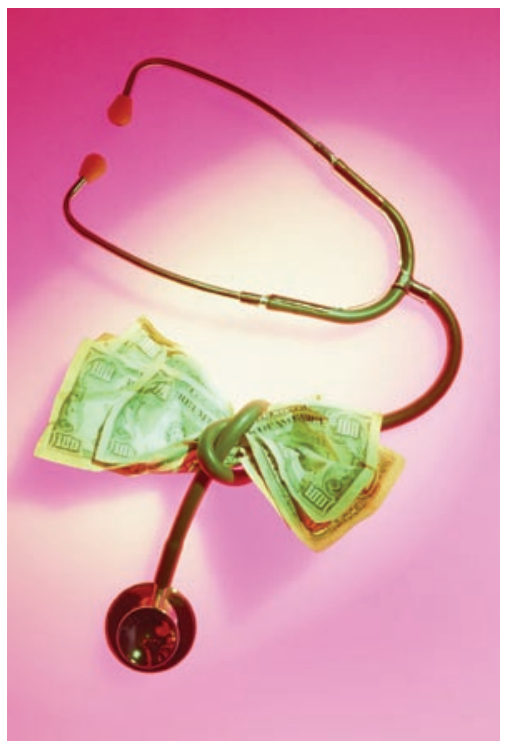

There are several ways in which payment might enhance recruitment. First, the offer of money as reimbursement for time or expenses incurred could help to make research participation a revenue-neutral activity for participants. In this regard, money may enable individuals to take part who otherwise could not afford to participate or who are not willing to make a financial sacrifice in order to do so. Alternatively, payment could help recruit individuals who believe they should be fairly compensated for their time and effort. Money can also serve as a recruitment incentive, especially if the amount offered is high enough to attract subjects to research and overcome inertia, lack of interest, as well as financial and other barriers (see Why pay clinical research subjects?). Some say that financial incentives are also necessary to overcome barriers unique to certain subgroups in the population, such as lack

\section{Figure 1}

Offering money to clinical research subjects for their participation is a fairly common practice in the US. Yet there is little consensus about why, when, or how much to pay these individuals. Getty Images.

of awareness or distrust. Consequently, money may not only be important to general recruitment but also helpful in achieving the goals of racial, ethnic, gender, and social diversity of subjects participating in biomedical research $(22,23)$.

However, empirical evidence demonstrating that payment is necessary and/or effective for the recruitment of clinical research subjects is limited. People appear to be attracted to research and motivated to participate for a variety of reasons. Healthy volunteers, who are frequently paid and unlikely to benefit medically from research participation, are often attracted to research and motivated to participate by money. Yet they appear to have a variety of other motives besides those of a financial nature for participation in research, including curiosity, altruism, sensation seeking, and desire for attention provided by physicians (24-26). Patient-subjects - those who suffer the disease or condition under study in a particular research protocol - are often motivated to participate by the hope of personal therapeutic benefit. When patient-subjects enroll in clinical studies and they understand the likelihood of direct medical benefit to be remote or nonexistent, their motivations are likely to be similar to those of healthy volunteers. Although patient-subjects are often offered payment for their participation in clinical studies, little research has been done to evaluate the extent to which money influences recruitment or their willingness to participate (21). Given the diverse motivations of subjects in clinical research and a lack of relevant data, it is difficult to know how much paying subjects helps to accomplish recruitment goals.

Similarly, there are few data to support the idea that paying subjects ensures diversity. In fact, other, less fungible factors, for example, lack of child care for women and long-standing

\section{Why pay clinical research subjects?}

\section{Reasons to pay research subjects}

Incentive necessary to recruit adequate numbers of research subjects

Incentive necessary to overcome opportunity costs, inertia, and distrust and recruit hard-to-reach subjects, especially underrepresented groups

Reimbursement for expenses (and possibly lost wages) to reduce the barrier of financial sacrifice for participants

Fair compensation or remuneration for the time and inconvenience of research participation

\section{Related comments and questions}

Limited data exist to document the extent to which money works as a recruitment incentive for clinical research or to show the value of money for recruitment compared with other powerful incentives, such as treatment or access to care

Limited data to support the claim that money increases diversity; Money may not overcome all barriers and in fact could contribute to, rather than diminish, suspicion or lack of trust

Not all research participants are reimbursed; Payment to individuals would vary based on their expenses and the value of their time

Data suggest that time may not be the main criterion for determining amounts of payment to subjects; Inconvenience is hard to quantify 


\section{Ethical concerns about the payment of research participants}

\section{Payment may be perceived as:}

Coercion

\section{Undue inducement}

May compromise informed consent by:

(a) reducing interest in understanding risks related to research; (b) reducing the voluntary nature of the decision to participate Money may unduly influence individuals to misrepresent themselves

Disproportionate research burden on the poor

Commodification

\section{Related comments and questions}

Coercion involves a threat of harm. Thus, an offer of money in return for research participation is not coercion.

Undue inducement is not well defined

Limited data suggest that payment does not affect understanding or perception of risk. The adequacy of understanding as part of informed consent can be assessed.

Voluntary decisions can be made when inducements are offered, even in the setting of limited or poor financial options

There are limited data on the influence of money on informed consent Other incentives may be as powerful as money

Careful eligibility screening can minimize risk of misrepresentation

Sociodemographics of research participants are not well known

Inadequate financial reimbursement might

disproportionately exclude the poor

Paid participation may be an opportunity, not a burden

Services offered as part of research participation are not the same as "selling" body parts or sex and may be of little risk to the health and well-being of the participant distrust of the research establishment by certain ethnic groups (27-30), may be obstacles to participation that money cannot overcome. Distrust, in fact, could plausibly be exacerbated by an offer of money.

\section{Ethical concerns about offering payment to research subjects}

Several ethical concerns have been raised regarding the payment of research participants (see Ethical concerns about the payment of research participants). The most commonly expressed concern is that payment could be coercive or serve as undue inducement to research participants. By definition, coercion is understood to involve a threat of physical, psychological, or social harm in order to compel an individual to do something, such as participate in research (31). However, money for research participation is an offer or an opportunity and not a threat and therefore cannot be perceived as coercion. But can money be considered an undue inducement? Existing guidelines warn against undue inducement and its potential to compromise informed consent, although there is disagreement about what exactly constitutes undue inducement and consequently disagreement about the extent to which it is a valid problem in research (32). The US Code of Federal Regulations requires that informed consent be obtained "under circumstances ... that minimize the possibility of coercion or undue influence" $(12,13)$. An inducement in clinical research, as defined in The official IRB guidebook (33), is deemed undue and therefore troublesome if it is so "... attractive that [it can] blind prospective subjects to potential risks or impair their ability to exercise proper judgment ..."

Do financial incentives blind potential research participants to the risks of research when making decisions regarding participation?
Motivated by cash payments or an attractive financial package, an individual could have less interest in evaluating or understanding study details, reading the consent form, or attempting to understand the goals, purposes, and risks associated with a study. This may be of little concern, however, if a clinical research protocol has almost no risks or has been approved by an IRB that has judged the level of risk to be acceptable (32). If, in addition, there are other mechanisms in place during the informed consent process to assure that participants adequately understand relevant risks (34), then this seems like a misplaced worry and may even represent "unwarranted paternalism" (35). Further, limited evidence suggests that the offer of payment does not obscure the risk perception of potential research participants $(20,21)$, and there are no data to suggest that it does.

Others worry that money can impair judgment or compromise voluntary decision making. But voluntary decisions are motivated by various factors, sometimes including money, and are not necessarily motivated by altruism alone. When people are choosing a job, making purchases, or making other voluntary decisions, they often consider the monetary aspects of their choice in the form of salary, benefits, or sales price. Decisions are generally complex and multifaceted, however, and are rarely based solely on monetary considerations. Similarly, people participate in clinical research for multiple reasons, and money may be one among those reasons or even the main reason. Limited data suggest that the offer of money is one factor in the decision making of some, but not all, potential participants $(21,24,36-40)$.

Even if money is one reason or the main reason to participate in research, does the offer of money impair judgment? In one study, most respondents $(75 \%)$ thought an offer of $\$ 500$ for research participation could impair the judgment of others, but many 


\section{Table 1}

Models of payment for the participation of research subjects

$\begin{array}{ccc}\text { Model } & \text { Payment serves as } & \text { Amount determined by } \\ \text { Market } & \text { Incentive } & \begin{array}{c}\text { Supply and demand; } \\ \text { market rates }\end{array}\end{array}$

Wage-

payment

Compensation

Standardized "wage" for time and effort, suggested to be commensurate with wages for unskilled, but essential jobs; additional payment for extra burdens such as endurance of uncomfortable procedures

Reimbursement Reimbursement Expenses incurred (transport, meals, lodging); with or without reimbursement for lost wages

(b) Little risk of undue inducement.

\section{Potential disadvantages}

(a) Undue inducement possibly resulting in: incomplete assessment of risks and benefits by subject; subject concealing information to ensure enrollment/retention.

(b) Competition between studies;

better-funded studies more likely to meet recruitment goals.

(c) Different levels of payment at different locations for multicenter trials.

(a) May have little impact on recruitment. (b) Might undercompensate some subjects in relation to regular wage and preferentially attract others. (c) Little or no financial

sacrifice for subject if

lost wages are reimbursed.

(c) Equal pay for equal work. (d) Less risk of undue inducement.

(a) Makes research participation revenue neutral.

(a) May have little impact on recruitment.

(b) Uneven reimbursement from subject to subject.

(c) Reimbursement costs for high-salaried subjects may result in the targeting of low-income populations.

(d) Financial sacrifice for subject if lost wages are not reimbursed.

(a) Likely to have no impact on recruitment.

(b) No basis for consistency.
Token of appreciation given at the conclusion of study
for contribution made.
(c) Avoids undue inducement.
(a) Expresses gratitude

Table modified from The New England Journal of Medicine (46).

fewer (20\%) thought it would impair their own judgment (41). Presumably, fewer people would think smaller amounts, say \$25 or even $\$ 100$, would impair judgment, yet most clinical research studies offer considerably less than $\$ 500$ for participation (6). Some worry that individuals with limited opportunities for earning money may be most susceptible to impaired judgment when faced with an offer of money (23). But, as Wilkinson and Moore argue, even people with few options may still have the ability to make decisions for themselves and thus be capable of autonomous consent (42). In fact, denying the possibility of payment to autonomous research subjects with limited opportunities for earning money further restricts their options rather than protecting them from a situation in which their judgment might be impaired, especially if they would still be invited to participate in research that did not offer compensation. Careful attention, during the process of obtaining informed consent, to subjects' understanding and expectations of clinical research and their sense of freedom to choose to participate or not may be more appropriate, albeit imperfect, than limiting the opportunity to receive payment for participation.

On the other hand, if offering a large amount of money could cause some people to agree to participate in research for which they would otherwise have a profound reluctance, the offer demonstrates disrespect for their deep reservations or preferences.
Limiting the amount of money offered for research participation might minimize the chances that it will unduly influence participants in this way $(43,44)$. In my view, offering modest amounts of money is unlikely to obscure risks or impair the judgment of most individuals. However, investigators and IRBs should review the offer of money and other inducements outlined in clinical research proposals, especially for research on the margin of reasonable risk or with groups of people that are more likely to be attracted by an offer of money. Additional empirical research would increase our understanding of the extent to which money influences decisions about research participation in relation to other factors; and to what extent, if at all, people actually do agree to participate in research that compromises their deeply held values or interests.

Concern has also been expressed about the potential for money to unduly influence ". . . subjects to lie or conceal information that if known would disqualify them from enrolling or continuing as participants in a research project" (43). Misrepresentation of previous or current medical problems could jeopardize both the safety of the subject and the quality or interpretability of the data. For example, an individual interested in a well-paying MRI study could jeopardize his safety by concealing the history of a shrapnel injury that otherwise would exclude him. A participant in a phase 1 drug study could fabricate side effects in order to stop 
study participation early without loss of payment, consequently jeopardizing the quality of the science. One study showed a willingness of subjects to conceal information from investigators in lower-risk studies, but this willingness was not associated with payment (20). It is unknown how often such misrepresentation occurs in clinical research and also unclear whether money is uniquely capable of inducing this kind of deception. Perhaps we should worry more about the possibility of desperate patients engaging in deception if they perceive the therapeutic intervention or agent under study to be their best or only remaining therapeutic option. Careful attention to eligibility criteria in the screening history, physical examination, and laboratory tests can minimize, although not eliminate, the possibility of misrepresentation in order to enroll in research trials. In addition, mechanisms such as prorating payments over time might help minimize the possibility of misrepresentation during a study.

Additional concerns about the ethics of offering payment to research subjects have received less attention. Some worry that payment might be more attractive to individuals with low socioeconomic status, and thus the payment of subjects could result in a disproportionate research burden on this population. In addition to worries about distributive justice, a skewed subject pool could confound the generalizability of data. Unfortunately, research subject sociodemographic information is not well documented; when documentation is available, it has been shown that subjects in at least some studies tend to be primarily insured and not economically disadvantaged (45). Interestingly, offering no money or such a small amount of money that participation in research is inaccessible to those who are economically disadvantaged also has the potential to skew the subject pool and contravene principles of distributive justice, especially for research perceived as beneficial to participants.

\section{Models of payment made to research subjects}

Assuming that paying research subjects is ethically acceptable, there still remain questions regarding how to pay subjects. Several possible models of payment capture the various ways that payment could be conceptualized and the amount of payment determined: a market model, a wage-payment model, a reimbursement model, and an appreciation model (46) (Table 1). In a market model, payment is designed to be a straightforward incentive. The amount of payment is determined by the market; that is, the value necessary to recruit the number and type of subjects needed in a given time frame. Consequently, studies that need to recruit individuals with rare conditions or characteristics may offer more money, while studies for which there are many willing participants may offer no money. According to the market concept, the amount of money could be increased to overcome aversion to risk or inconvenience. Completion bonuses and escalating incentives would be commonly employed as incentives for subjects to meet data points or complete a study. In contrast, in a wage-payment model, subjects are offered payment as compensation for the time and contribution they make to the research. Money offered to subjects is calculated by a standardized hourly "wage" offered to compensate for their hours of participation, with reasonable additions made for added inconvenience. In a reimbursement model, payment is offered to research participants to reimburse them for actual expenses, such as travel, meals, and parking. One version of a reimbursement model would also offer reimbursement for lost wages. If the latter were adopted, subjects in the same study might be reimbursed at radically different rates, depending on their occupation and normal salary. An appreciation model conceives of money as a reward or token of appreciation for a subject's contribution to research. Appreciation can be shown by awarding a wide range of amounts of money as well as nonmonetary gifts. Unlike the other 3 models, appreciation payments may have little impact on study recruitment, as appreciation is often reserved until the study ends. Elsewhere, my colleagues and I have argued that conceptualizing payment as compensation in the form of a wage payment is the most ethically appropriate model because it recognizes the contribution subjects make to research and is relatively standardized across studies. While still possibly able to facilitate recruitment, wagelike payments are unlikely to unduly influence individuals to enroll in research to which they object (46). Finally, offering fair compensation for research participation also demonstrates that society values clinical research and is grateful for subjects' contribution to the common good.

\section{Payment of healthy subjects versus patient-subjects}

Commentators sometimes assume or assert that it is legitimate to pay healthy subjects but not patient-subjects for their participation in research (10). Healthy subjects are often motivated by money to participate in research, receive little or no benefit from participation, and may appropriately be considered independent contractors in research (40). Paying money to healthy volunteers is widely accepted, although concerns about undue inducement and distributive justice may still pertain. In contrast, although patient-subjects are often paid to participate in research (5), commentators worry about paying patient-subjects because of their "vulnerability" (10). Certainly illness can make people vulnerable in multiple ways. Presumably, patient-subjects are considered more vulnerable in research studies than healthy subjects because of the nature of the relationship with their physician and because of possible confusion about the difference between participation in clinical research and the receipt of clinical care - the so-called therapeutic misconception (47). Although this is an empirical question, it is at least plausible that offering payment to patient-subjects in research could help them distinguish participation in a research study from the receipt of clinical care and thus actually decrease their vulnerability. Offering money in return for participation might also enable a patient to say no to the physician instead of feeling obligated to do what the physician suggests.

Payment may not be necessary for recruiting patient-subjects into research, especially if they are motivated by an opportunity for therapeutic benefit. However, if the goal of payment is to reduce the financial sacrifice that research subjects have to make, to compensate people for their time, or to show appreciation for their contribution, patient-subjects are equally deserving and should be paid comparably to healthy subjects. When patient-subjects participate in research that offers them desirable therapeutic benefits, money may seem irrelevant and unnecessary, even though not morally objectionable. However, when patientsubjects and healthy subjects are both asked to undergo certain identical study procedures for research purposes, in the interest of fairness, the 2 sets of individuals should be compensated similarly, as both are contributing to the development of generalizable knowledge to benefit others. 


\section{Payment of children in research}

Offering payment in pediatric research involves special challenges not found in research with consenting adults. First, research with children is vital and promoted by both the FDA (48) and the NIH (49). However, children do not provide their own consent to research but are enrolled by their parents or legal guardians, generally in accord with the child's best interests. Payment to parents for their child's research participation could potentially sway parental decisions in favor of participation since there is no personal risk to themselves. To avoid making children commodities, some argue that parents should not receive money as incentive for their child's research participation $(50,51)$. However, making it possible for a child to participate in research can be inconvenient and costly for parents, and the amount of risk children can be exposed to in research is strictly limited by federal regulations (52). Consequently, some find carefully calculated payment to compensate parents for time and inconvenience acceptable and unlikely to contribute to significant distortions in parental judgment (53), while others believe that compensation to parents should be limited to reimbursement for expenses (51). The American Academy of Pediatrics recommends the giving of gifts instead of money to children in a post-trial appreciation model (54), although many institutions do not appear to follow these recommendations (55). Giving money or non-cash gifts to children directly instead of to their parents is also difficult because children appreciate money and gifts differently depending on their age. Further empirical and conceptual research is needed to resolve when and how payment should be offered in pediatric research.

\section{Practical suggestions}

When deciding whether to offer payment to research participants in a study, investigators should take into account the nature of the study, the nature of participant contributions and vulnerabilities, institutional or organizational guidelines, and local societal and cultural norms. In the research proposal submitted to their IRB, investigators should describe the rationale for payment, how the dollar amount was calculated, and how and when payment will be made. Payment information should also be included in consent forms.

Although payment may be a factor in a subject's decision regarding research participation, IRBs do not consider payment a benefit to offset research risks when deciding whether or not to approve a study. IRBs evaluate whether the risks in a research study are justified by potential benefits; otherwise unacceptable risks cannot be made acceptable by offering money to subjects. Therefore, discussion of payment should only arise after the riskbenefit ratio of a study is found ethically acceptable. IRBs should review the justification for and the amount and schedule of payment and decide whether these variables are appropriate given the particular study and the population to be recruited. In making this determination, an IRB should consider study risks, potential vulnerabilities of the targeted subject population, eligibility criteria and screening plans, proposed methods for assessing subjects' knowledge of risks and ability to make voluntary autonomous decisions, and local norms. An IRB should also review the presentation of information about payment in consent documents as well as related advertisements and information sheets.

Plans for how and when money will be disbursed are also important. Prorating payment for studies involving multiple visits minimizes the possibility of inappropriately influencing someone to remain in a study just to receive a lump sum pay- ment at the end. Payment according to actual time and procedures completed is consistent with offering money as compensation for a subject's time and inconvenience. On the other hand, in longitudinal or long-term studies, where certain data points are critical to the study, it may be appropriate to use escalating incentives or completion bonuses, as long as they are not offered to compensate for increasing risk. These strategies should be approved by the relevant IRB.

\section{Empirical studies and unanswered questions}

Although there is a growing volume of empirical research addressing issues related to the ethics of paying research subjects, many more questions need attention. As mentioned above, evaluating whether or under what research circumstances money might impair a subject's judgment would be important, as well as the extent to which payment leads people to participate against deep objections. Payment to clinical research populations who are particularly vulnerable to exploitation, such as children, substance users, or those unable to consent for themselves, warrants further attention. Sociodemographic data on research subjects in both paid and unpaid studies would be useful. More specific guidance, including benchmarks, would greatly assist investigators and IRBs in making decisions about payment for participation. Additional understanding of variation in local or regional norms and participants' values as they relate to money, as well as how to consider the economic conditions in communities in which research will be conducted in formulating an approach to payment, would be useful, especially for multicenter and multinational studies. Additionally, more attention to the influence of nonmonetary incentives and compensation is warranted, although many of the concerns are similar.

\section{Concluding remarks}

Payment to research subjects for their participation is a pervasive yet uneven practice in the US. Although there is nothing inherently unethical about paying clinical research subjects, knowing more about its effect on recruitment and its use in different research circumstances is critical. Investigators might offer money to research subjects as an incentive to participate, as fair compensation for their contribution, and/or as a way to reduce any related financial sacrifice. Worries about undue inducement can be reduced by careful assessment of risks as well as attention to eligibility criteria and to the informed and voluntary consent of research subjects. Further dialogue, conceptual analysis, and empirical work about payment made to clinical research subjects may serve to reduce the divide between those who object to such payment and those who promote payment as a sign of respect for the contributions of research subjects and a way to facilitate valuable research.

\section{Acknowledgments}

I would like to thank Neal Dickert for important insights, for many fruitful discussions and collaborations on this topic, and for his critical review of this manuscript. The views expressed here are those of the author and do not necessarily reflect the views or policies of the NIH or the US Department of Health and Human Services.

Address correspondence to: Christine Grady, Department of Clinical Bioethics, Clinical Center, NIH, Building 10/Room 1C118, Bethesda, Maryland 20892, USA. Phone: (301) 435-8710; Fax: (301) 496-0760; E-mail: cgrady@nih.gov. 
1. Lederer, S. 1995. Subjected to science: human experimentation in America before the Second World War. The Johns Hopkins University Press. Baltimore, Maryland, USA. 192 pp.

2. NIH. 1959. Healthy volunteers help scientists conquer disease. U.S. Department of Health, Education and Welfare, Public Health Service, NIH. Bethesda, Maryland, USA. 15 pP.

3. Center Watch Clinical Trials Listing Service. http:// www.centerwatch.com.

4. Dickert, N., Emanuel, E., and Grady, C. 2002. Paying research subjects: an analysis of current policies. Ann. Intern. Med. 136:368-373.

5. Grady, C., Dickert, N., Jawetz, T., Gensler, G., and Emanuel, E. 2005. An analysis of U.S. practices of paying research participants. Contemp. Clin. Trials. 26:365-375.

6. Center Watch Clinical Trials Listing Service. Clinical trial listings by medical areas. http://www.centerwatch.com/patient/trials.html.

7. McNeill, P. 1997. Paying people to participate in research: why not? Bioethics. 11:390-396.

8. US FDA. 1998. Guidance for institutional review boards and clinical investigators: payment to research subjects. http://www.fda.gov/oc/ohrt/ irbs/default.htm.

9. Dunn, L., and Gordon, N. 2005. Improving informed consent and enhancing recruitment for research by understanding economic behavior. J. Am. Med. Assoc. 293:609-612.

10. Lemmens, T., and Elliott, C. 2001. Justice for the professional guinea pig. Am. J. Bioeth. 1:51-53.

11. Wilkinson, M., and Moore, A. 1999. Inducements Revisited. Bioethics. 13:114-130.

12. US Department of Health and Human Services and NIH Office for Protection from Research Risks. 2001. Protection of human subjects. US Code of Federal Regulations, title 45, part 46. http://www.hhs.gov/ ohrp/humansubjects/guidance/45cfr 46 .htm.

13. US FDA. 2004. Protection of human subjects. US Code of Federal Regulations, title 21, part 50. http://www.accessdata.fda.gov/scripts/cdrh/ cfdocs $/ \mathrm{cfcfr} /$ CFRSearch.cfm?CFRPart $=50$.

14. Asch, D., Christakis, N., and Ubel, P. 1998. Conducting physician mail surveys on a limited budget: a randomized trial comparing $\$ 2$ bill versus $\$ 5$ bill incentives. Med. Care. 36:95-99.

15. Church, A. 1993. Estimating the effect of incentives on mail survey response rates: a meta-analysis. Public Opin. Q. 5:62-79.

16. Doody, M., et al. 2003. Randomized trial of financial incentives and delivery methods for improving response to a mailed questionnaire. Am. J. Epidemiol. 157:643-651

17. Halpern, S., Ubel, P., Berlin, J., and Asch, D. 2002. Randomized trial of $\$ 5$ versus $\$ 10$ monetary incentives, envelope size, and candy to increase physician response rates to mailed questionnaires. Med. Care. 40:834-839.

18. VanGeest, J., Wynia, M., Cummins, D., and Wilson, B. 2001. Effects of different monetary incentives on the return rate of a national mail survey of physicians. Med. Care. 39:197-201.
19. Warriner, K., Goyder, J., Gjertsen, H., Hohner, P., and McSpurren, K. 1996. Charities, no; lotteries, no; cash, yes: main effects and interactions in a Canadian incentives experiment. Public Opin. Q. 60:542-562.

20. Bentley, J., and Thacker, P. 2004. The influence of risk and monetary payment on the research participation decision making process. J. Med. Ethics. 30:293-298.

21. Halpern, S., Karlawish, J., Casarett, D., Berlin, J., and Asch, D. 2004. Empirical assessment of whether moderate payments are undue or unjust inducements for participation in clinical trials. Arch. Intern. Med. 164:801-803.

22. Russell, M., Moralejo, D., and Burgess, E. 2000. Paying research subjects: participants' perspectives. J. Med. Ethics. 26:126-130.

23. Grant, R., and Sugarman, J. 2004. Ethics in human subjects research: do incentives matter? J. Med. Philos. 29:717-738.

24. Bigorra, J., and Banos, J. 1990. Weight of financial reward in the decision by medical students and experienced healthy volunteers to participate in clinical trials. Eur. J. Clin. Pharmacol. 38:443-446.

25. Farre, M., Lamas, X., and Cami, J. 1995. Sensation seeking among healthy volunteers participating in phase I clinical trials. Br. J. Clin. Pharmacol. 39:405-409.

26. Cunny, K., and Miller, H. 1994. Participation in clinical drug studies: motivations and barriers. Clin. Ther. 16:273-282.

27. Corbie-Smith, G., Thomas, S.B., and St. George, D. 2002. Distrust, race, and research. Arch. Intern. Med. 162:2458-2463.

28. Corbie-Smith, G., et al. 2003. Influence of race, clinical, and other socio-demographic features on trial participation. J. Clin. Epidemiol. 56:304-309.

29. Harris, Y., et al. 1996. Why African Americans may not be participating in clinical trials. J. Natl. Med. Assoc. 88:630-634.

30. Shavers, V.L., Lynch, C.F., and Burmeister, L.F. 2000. Knowledge of the Tuskegee study and its impact on the willingness to participate in medical research studies. J. Natl. Med. Assoc. 92:563-572.

31. Faden, R., and Beauchamp, T. 1986. History and theory of informed consent. Oxford University Press. New York, New York, USA. 392 pp.

32. Emanuel, E.J. 2004. Ending concerns about undue inducement. J.Law Med. Ethics. 32:100-105.

33. Office for Protection from Research Risks. 1993. IRB guidebook. Washington, DC, USA. http:// www.hhs.gov/ohrp/irb/irb_guidebook.htm

34. Grady, C. 2001. Money for research participation: does it jeopardize informed consent? Am. J. Bioeth. 1:40-44.

35. Newton, L. 1982. Inducement, due and otherwise IRB. 4:4-6.

36. Aby, J., Pheley, A., and Steinberg, P. 1996. Motivations for participation in clinical trials of drugs for the treatment of asthma, seasonal allergic rhinitis, and perennial nonallergic rhinitis. Ann. Allergy Asthma Immunol. 76:348-354.

37. Hassar, M., et al. 1977. Free-living volunteer's moti- vations and attitudes toward pharmacological studies in man. Clin. Pharmacol. Ther. 21:515-519.

38. Korn, J., and Hogan, K. 1992. Effect of incentives and aversiveness of treatment on willingness to participate in research. Teach. Psychol. 19:21-24.

39. van Gelderen, C., Savelkoul, T., van Dokkum, W., and Meulenbelt, J. 1993. Motives and perceptions of healthy volunteers who participate in experiments. Eur. J. Clin. Pharmacol. 45:15-21.

40. Tishler, C., and Bartholomae, S. 2002. The recruitment of normal healthy volunteers: a review of the literature on the use of financial incentives. J. Clin. Pharmacol. 42:363-373.

41. Casarett, D., Karlawish, J., and Asch, D. 2002. Paying hypertension research subjects. J. Gen. Intern. Med. 17:650-652.

42. Wilkinson, M., and Moore, A. 1997. Inducement in research. Bioetbics. 11:373-389.

43. Macklin, R. 1981. On paying money to research subjects: 'due' and 'undue' inducements. IRB. 3:1-6.

44. Ackerman, T. 1989. An ethical framework for the practice of paying research subjects. IRB. 11:1-4.

45. Pace, C., Miller, F., and Danis, M. 2003. Enrolling the uninsured in clinical trials: an ethical perspective. Crit. Care Med. 31:S121-S125.

46. Dickert, N., and Grady, C. 1999. What's the price of a research subject? Approaches to payment for research participation. N. Engl.J. Med. 341:198-203.

47. Appelbaum, P., et al. 1987. False hopes and best data: consent to research and the therapeutic misconception. Hastings Cent. Rep. 17:20-24.

48. US FDA. 2003. The Pediatric Research Equity Act of 2003. http://www.fda.gov/opacom/laws/prea.html.

49. NIH. 1998. NIH policy and guidelines on the inclusion of children as participants in research involving human subjects. NIH Guide Grants Contracts. http:/grants.nih.gov/grants/guide/notice-files/ not98-024.html.

50. Medicines and healthcare products regulatory agency. 2001. Clinical trials directive (2001/20/EC). Official Journal of the European Communities. 147:41.

51. Institute of Medicine. 2004. Payments related to children's participation in clinical research. Chapter 6. Ethical conduct of clinical research involving children. M. Field and R. Berman, editors. The National Academies Press. Washington, DC, USA. 211-228.

52. US Department of Health and Human Services and NIH. 2001. Additional DHHS protections for children involved as subjects in research. US Code of Federal Regulations, title 45, part 46, subpart D. http://www.hhs.gov/ohrp/humansubjects/ guidance $/ 45$ cfr 46 .htm\#subpartd.

53. Wendler, D., Rackoff, J., Emanuel, E., and Grady, C. 2002. The ethics of paying for children's participation in research. J. Pediatr. 141:166-171.

54. American Academy of Pediatrics, Committee on Drugs. 1995. Guidelines for the ethical conduct of studies to evaluate drugs in pediatric populations. Pediatrics. 95:286-294.

55. Weise, K.L., et al. 2002. National practices regarding payment to research subjects for participating in pediatric research. Pediatrics. 110:577-582. 